\title{
Assessment of Barriers to Prevent the Development of Potato Tuber Blight Caused by Phytophthora infestans
}

\author{
J. R. Glass, K. B. Johnson, and M. L. Powelson, Department of Botany and Plant Pathology, Oregon State Uni- \\ versity, Corvallis 97331-2902
}

\begin{abstract}
Glass, J. R., Johnson, K. B., and Powelson, M. L. 2001. Assessment of barriers to prevent the development of potato tuber blight caused by Phytophthora infestans. Plant Dis. 85:521-528.
\end{abstract}

Experiments were conducted in an irrigated, sandy loam soil to evaluate mulches and hill sizes as barriers to prevent the development of potato tuber blight caused by Phytophthora infestans. In mulching experiments, five treatments were applied to field plots of cv. Red LaSoda: 1, no mulch; 2, polyurethane spray foam in an 8 -cm-diameter area immediately surrounding the plant stem; 3, black polyethylene film over the entire hill except near the stem; 4, a combination of treatments 2 and 3; and 5, a water-permeable, agricultural textile treated with copper hydroxide applied over the same hill area as in treatment 3. In 1998, the incidence of tuber blight in plots mulched with black film (treatments 3 and 4 ) averaged 32\% compared with 56\% in plots without this mulch (treatments 1 and 2). In 1999, incidence of tuber blight in plots with and without black film averaged 9 and 20\%, respectively. Mulching the stem area with spray foam (treatments 2 and 3) did not reduce the incidence of blighted tubers when compared with the appropriate control. The copper-treated textile mulch (treatment 5) provided reductions in the incidence of tuber blight similar to those observed with the use of black polyethylene film. In a hill size experiment conducted once in 1998 and twice in 1999, three hill size treatments were established on cvs. Red LaSoda, Shepody, and Russet Burbank. Red LaSoda was the most susceptible and Russet Burbank the least susceptible to tuber blight. Comparison of blight incidence in tubers classified by depth in the hill revealed few differences among the hill size treatments, although over all treatments, tubers covered with more than $15 \mathrm{~cm}$ of soil had a lower incidence of blight (1 to 14\%) than tubers with less soil cover (13 to 59\%). Most tuber infections were apparently initiated in eyes and were not concentrated on a portion of the tuber such as the stolon (proximal) or distal end. The fact that black film and textile mulches reduced tuber infection indicates that inoculum of $P$. infestans can move from foliage to tubers through soil and that inoculum movement is not limited to large channels in the hill such as those created by the potato stems. The mulch treatments, however, provided only partial protection of tubers, limiting the practicality of such treatments to commercial producers. Hill size treatments had little effect on tuber blight incidence, indicating that adequate suppression of tuber infection in an environment conducive to late blight may be inseparably linked to adequate suppression of the foliar phase.

Additional keywords: plant disease control

Late blight, caused by Phytophthora infestans (Mont.) de Bary, is a devastating disease of potato foliage and tubers, reducing crop quantity and quality. Additional costs are incurred when money is spent on management practices to suppress the disease. During the late 1980s and 1990s, introduction of new clonal lineages of $P$. infestans to potato growing areas of the world led to severe late blight outbreaks $(9,10,12)$. These new clonal lineages created disease management challenges because many were resistant to the fungicide metalaxyl, which had become an inte-

Corresponding author: K. B. Johnson

E-mail: johnsonk@bcc.orst.edu

Accepted for publication 2 February 2001.

Publication no. D-2001-0309-01R

(C) 2001 The American Phytopathological Society

into the soil $(14,15,18,23)$. Lacey (15) attributed high incidences of blight in tubers clustered around the potato stem to inoculum moving in water channeling down cracks in the soil created by the potato stem. He did not, however, quantify the relative importance of this route of inoculum movement to the overall incidence of tuber blight. In contrast, Dubey and Stevenson (8) demonstrated that as little as $0.6 \mathrm{~cm}$ of water, when applied to soil columns containing sandy loam soil, could carry sporangia to a depth of $40 \mathrm{~cm}$. Under natural conditions, tuber blight is initiated most often at eyes, lenticels, and wounds $(1,16,22)$. In this regard, use of large potato hills is commonly recommended as a cultural practice that can protect tubers from blight by filtering spores out of the soil water suspension and by reducing direct contact of inoculum on tubers $(13,19)$. Data supporting this recommendation, however, are limited, particularly with respect to the new lineages of $P$. infestans, the amount of soil required to protect tubers, and the relative value of this practice to other late blight suppression tactics. In addition, judging from the lack of published information, the potential for suppression of tuber blight through application of barriers other than soil has received little research effort.

The purpose of this study was to examine the relative importance of different cultural barriers on the field development of tuber blight caused by $P$. infestans.

gral tool for foliar late blight suppression. The new lineages quickly displaced the older, previously established clones $(2,21)$. In addition, new clonal lineages were apparently more aggressive on potato tubers than the older $P$. infestans clones that growers had learned to manage (17). The increased incidence of tuber blight has led to a new emphasis on management of tuber infection, which remains the least understood part of the late blight disease cycle.

Because soilborne oospores of $P$. infestans are rare in most potato production systems in the United States and Canada, infection of potato tubers in the field is initiated most commonly by inoculum, i.e., sporangia and zoospores, produced on the plant foliage. Thus, developing tubers can become blighted shortly after late blight is established on potato foliage (11). Once the inoculum produced on the foliage is deposited onto the surface of the potato hill, water from irrigation or rain can carry it

\section{MATERIALS AND METHODS}

Mulching experiment. Field plot preparation and experimental design. Potato field plots were established in sandy loam soils on 9 June 1998 and 24 May 1999 at the Department of Botany and Plant Pathology Field Laboratory near Corvallis, OR. Each experimental plot contained two rows of 15 plants of potato (Solanum tuberosum) cv. Red LaSoda spaced $46 \mathrm{~cm}$ within rows and $86 \mathrm{~cm}$ between rows. Thirty-five (1998) or 40 plots (1999) were established, each separated by a meter of bare soil. Mulching treatments were assigned to plots in a randomized complete block design with seven (1998) or eight (1999) replicates.

In both years, 15-15-15 fertilizer $(\mathrm{N}$, $\mathrm{P}_{2} \mathrm{O}_{5}, \mathrm{~K}_{2} \mathrm{O}$ ) at $84 \mathrm{~kg} / \mathrm{ha}$ was banded into rows at planting, followed 4 weeks after planting (i.e., time of hilling) by a top dressing of 15-15-15 fertilizer at 16.8 
$\mathrm{kg} / \mathrm{ha}$ in 1998 or $45-0-0$ urea at $25.2 \mathrm{~kg} / \mathrm{ha}$ in 1999 . The potatoes were hilled by running tractor-mounted disks over the plots. After hilling and prior to treatment establishment, potato plants were thinned to a single stem. Weeds were suppressed by hand hoeing with supplementary spot treatments of glyphosate (RoundUp Ultra, $1.5 \%$, Monsanto, St. Louis, MO) on 12 July and 3 August 1998, and 1 July and 18 August 1999. On 22 June 1999, s-ethyl dipropylthiocarbamate (Eptam 7-E, 3.5 liters/ha, Zeneca Ag Products, Wilmington, DE) also was sprayed between the hills to control the emergence of purple nutsedge, Cyperus rotundus, and other weeds. To prevent the potential early onset of foliar late blight, chlorothalonil (Bravo Weather Stik, Zeneca Ag Products, Wilmington, DE) was applied in 1998 at rates of 0.7 liter/ha on 17 July, 1.5 liters/ha on 27 July, and 2.2 liters/ha on 5 and 12 August, and in 1999 , at the rate of 0.9 liter/ha on 22 June and 2 July. Overhead sprinklers were used to apply $4 \mathrm{~cm}$ of water twice a week throughout the season.

Texture of the soil in the study area was determined by the Soil Physical Characterization Laboratory, Department of Crop and Soil Science, Oregon State University. Soils were characterized in 1998 as $49.1 \%$ sand, $36.6 \%$ silt, and $14.3 \%$ clay, and in 1999 as $72 \%$ sand, $18.9 \%$ silt, and $9.1 \%$ clay. Air temperatures were recorded at weather stations located at the Field Laboratory. Near the end of the 1999 growing season, a CR21X data micrologger (Campbell Scientific, Logan, UT) with eight temperature probes monitored soil temperatures in two plots of each of four treatments. Temperature probes were buried in soil at approximately $10 \mathrm{~cm}$ below the crest of the hill, i.e., where the majority of the tubers grew. Relative soil moisture was monitored between 1 September and 4 October 1999 using tensiometers (Irrometer Company Inc., Riverside, CA) placed at both the crest and the base of the hills in two plots of all five mulching treatments.

Treatment establishment. Mulching treatments were designed to block the movement of $P$. infestans inoculum traveling from foliage to tubers in two regions of the potato hill: the area immediately surrounding the potato stem and the remainder of the hill surface. The mulching treatments were: 1 , no mulch; 2 , expandable polyurethane spray foam in the $8-\mathrm{cm}$ diameter area immediately surrounding the potato stem; 3, black polyethylene film over the entire hill surface except the 8$\mathrm{cm}$-diameter area immediately surrounding the potato stem; 4, combination of treatments 2 and 3 ; and 5, copper hydroxidetreated $\left(6 \mathrm{~g} / \mathrm{m}^{2}\right)$ agricultural textile (Tex-RPro, Texel, Saint-Elzéar-de-Beauce, Quebec, Canada) applied over the same area as in treatment 3. The objective of spraying expandable polyurethane spray foam into the area immediately surrounding the plant stem was to block the passage of inoculum-laden water down the channels in the soil created by the emergence of the potato stem. Black polyethylene film placed along the surface of the potato hill prevented water and inoculum penetration on the hill surface, whereas copper hydroxide-treated textile did not prevent water penetration of the hill. Treatments, with the exception of the spray foam mulch, were established 5 weeks after planting. For all treatments except the copper hydroxide-treated textile, the area immediately surrounding the potato stem was separated from the rest of the hill by vertically positioning a $15-\mathrm{cm}$ segment of 8-cm-diameter PVC pipe vertically around the stem of each potato plant. Care was taken to avoid damaging potato stems or roots during placement of the PVC pipe. Black polyethylene film cut to 0.8 by $9.6 \mathrm{~m}$ (152 $\mu \mathrm{m}$ thick) was placed over each row of the film plots with cuts made to accommodate the PVC pipes and potato stems. Copper hydroxide-treated textile was cut into 1 by $9.6 \mathrm{~m}$ strips and positioned similarly. Spray foam treatments were established in mid-August of both years, prior to inoculation with $P$. infestans. Polyurethane spray foam (Great Stuff, Flexible Products Co., Joliet, IL) was sprayed into the area within the PVC pipe and allowed to cure to form a tight seal between the potato stem and PVC pipe. These seals were inspected routinely, and spray foam was reapplied if gaps appeared.

Inoculation and epidemic development. In 1998, inoculum of $P$. infestans (US-8) was obtained by collecting leaves with sporulating late blight lesions from a nearby potato field. Sporangia were washed into distilled water $\left(\sim 10^{3}\right.$ sporangia per $\mathrm{ml}$ ) and sprayed onto the plots at dusk with a backpack sprayer equipped with a hand wand. Dates of inoculation were 27 August and 10 and 17 September. In 1999, inoculum was obtained from laboratorygrown cultures of a $P$. infestans isolate (US-8) maintained on rye and pea agar at $18^{\circ} \mathrm{C}$ in the dark. Sporangia were suspended in distilled water at a concentration of $10^{4}$ sporangia per $\mathrm{ml}$ and were sprayed in early evening on 27 and 31 August. In both years, plots were irrigated at dusk for 15 to $30 \mathrm{~min}$ daily throughout September to promote an environment conducive to the development of foliar late blight. As the foliar blight epidemics developed, visual assessments of the percentage of foliage diseased were recorded every 4 days (18).

Treatment evaluation. In each season, tuber harvest began when 75 to $100 \%$ of the potato foliage had become blighted and continued over the next 6 to 10 days. Six potato plants were selected randomly from each plot for hand harvest. During harvest, haulms were removed and tubers were dug carefully by hand and separated into three depth classifications based on tuber location within the hill: (i) shallow or exposed tubers that were not completely covered with soil and grew at the surface of the potato hill; (ii) intermediate tubers that grew within the first $15 \mathrm{~cm}$ of the hill surface and were completely buried by soil; and (iii) deep tubers that were covered by more than $15 \mathrm{~cm}$ of soil. Tubers from each location in each hill were placed separately into plastic bags and stored in an unheated $\left(6\right.$ to $\left.9^{\circ} \mathrm{C}\right)$ area until assessment.

All tubers were washed, weighed, and assessed for blight within 2 weeks of harvest. Washed tubers were examined for the presence or absence of lesions symptomatic of late blight. As part of the assessment, lesions were sliced to confirm the presence of brown discoloration in the tuber beneath the lesion, a symptom typical of late blight tuber infection (3). In 1999, the diagnosis of tuber blight was further confirmed by observing sporangia production after incubating a sample of tubers with characteristic lesions in plastic containers containing moist paper towels. The incidence of tuber blight was calculated as the percentage of total tubers showing late blight symptoms. The severity of blight on a tuber was recorded by estimating the percentage of tuber surface covered by the lesion. When possible to distinguish, the morphological feature of the tuber near the center of the lesion, typically an eye or the stolon, was recorded. A sample of apparently healthy tubers was stored at $2.2^{\circ} \mathrm{C}$ in the dark for a month and then evaluated for the presence of tuber blight symptoms, including external lesions and the underlying tuber discoloration, to determine the incidence of nonsymptomatic tuber infection at harvest. Estimates of the incidence of nonsymptomatic tuber infection were made from 728 tubers in 1998 and 1,832 tubers in 1999; these samples represented one-quarter (1998) and one-third (1999) of the nonsymptomatic tubers harvested in each experiment.

Data analysis. The relative severities of the foliar epidemics were summarized by computing the area under disease progress curve (AUDPC) for each plot (18). Plot averages of tuber blight incidence were transformed to stabilize variation among treatments using the arcsine square root transformation. No transformation was needed for plot averages of tuber yield or number. Effects of mulching treatments on foliar AUDPC values, incidences of tuber blight, tuber yield, and number of tubers per hill were evaluated by analysis of variance (ANOVA) (PROC MIXED, Statistical Analysis Software System, release 6.12 for Windows, SAS Institute, Cary, NC). Multivariate analysis of variance (MANOVA) (PROC GLM) was used to further evaluate effects of mulches on the three tuber-based dependent variables divided among the three hill depth classifications. In ANOVA and MANOVA models, the effects of 
block, black polyethylene film, polyurethane spray foam, and an interaction between black polyethylene film and spray foam on the measured responses were compared. In a second ANOVA model, effects of no mulch, copper hydroxidetreated textile, and black polyethylene film treatments were compared. If the $F$ value was significant $(P \leq 0.05)$, treatment means were then separated by Fisher's protected least significant difference. Daily mean soil temperatures recorded for three of the mulch treatments in 1999 were compared with the no-mulch control using a paired $t$ test. Frequency distributions of lesions located at the eye and stolon end of tubers were calculated for the five mulching treatments. The lesion location distributions for black polyethylene film, polyurethane spray foam, combination of film and spray foam, and copper hydroxidetreated textile were compared with the nomulch control using a chi-square test with one degree of freedom.

Hill size experiment. Field plot preparation and experimental design. Hill size experiments were established next to the mulching experiment in both years. On 9 June 1998 and 24 May 1999, cut seed pieces of cvs. Russet Burbank, Red LaSoda, and Shepody were planted into plots containing three rows of 20 seed tubers each; plant spacing was $46 \mathrm{~cm}$ within row and $86 \mathrm{~cm}$ between rows. In 1999, potatoes for an additional hill size trial were planted on 10 June with similar plant spacing but only 15 seed tubers per row. Cultivar plots were planted side by side in 1998 , while in 1999 a spacer row of bare soil was added to separate plots of different cultivars. Each cultivar plot was replicated six times for a total of 18 whole plots per trial. Whole plots were divided into three hill size treatments for a total of 54 subplots per trial. Crop maintenance was identical to that described for the mulching experiment, with the exception that the second 1999 hill size trial was top-dressed with fertilizer on 8 July.

Treatment establishment. Hill size treatments were assigned randomly to each row of the cultivar whole plot. The small hill size was established by using the planter hill only. The medium and large hill sizes were established by running tractor-mounted disks over the plots once or twice, respectively. Dates of supplementary hilling were 10 July 1998 and 21 June (first planting) and 9 July (second planting) 1999. Additional soil was shoveled onto the largest hill treatment shortly after the tractor operation in 1999 to assure that the differences in size between the larger two hills were more distinct than they were in 1998.

Cross-sectional areas of hills in each experiment were measured on six hills for each treatment. The hill profile was drawn onto a sheet of metal placed crosssectionally through the hill (1998) or by measuring the hill width and the length of a piece of wire stretched taut over the surface of the hill in 1999. Hill profiles were transferred to paper, cut out, and weighed. Areas of the hill profiles were calculated by dividing the weight of the paper profile by the weight of $1 \mathrm{~cm}^{2}$ of the same paper. In 1998, cross-sectional areas of the small, medium, and large hills averaged $263 \pm 23$ (s.e.), $494 \pm 19$, and $662 \pm 33 \mathrm{~cm}^{2}$ of soil, respectively. The 1999 small, medium, and large hill sizes were measured to contain $325 \pm 40,585 \pm 22$, and $961 \pm 34 \mathrm{~cm}^{2}$ of soil, respectively, in the first trial, and 213 $\pm 31,626 \pm 37$, and $1055 \pm 56 \mathrm{~cm}^{2}$ of soil, respectively, in the second trial.

Inoculation and treatment evaluation. Methods of inoculation, plot irrigation, measurement of foliar epidemic, tuber harvest, and tuber blight assessment were as described in the mulching experiment. In 1999, the Red LaSoda and Shepody plots from both experiments were harvested first, as the Russet Burbank plots had a slower rate of foliar epidemic progress.

Data analysis. Data analysis was conducted as described for the mulching experiment. ANOVA and MANOVA models were used to assess the effects of block, cultivar, hill size, and interaction of cultivar and hill size on the measured responses of foliar AUDPC values, tuber blight incidence, tuber yield, and number.

\section{RESULTS}

Foliar epidemic and environmental conditions. Each season, inoculation of potato foliage with $P$. infestans led to the establishment of a foliar late blight epidemic in the experimental plots. Date of epidemic onset was approximately 25 September in 1998 and 5 September in 1999 (Fig. 1A to E). After establishment, epidemics progressed rapidly, with over $80 \%$ of the foliage blighted within 3 weeks. Potato stems as well as leaves were blighted. Mulching treatments applied to cultivar Red LaSoda had no effect $(P>$ 0.1) on foliar AUDPC values, a result that was also evident in graphical comparisons of the disease progress curves (Fig. 1A and C). In 1999 hill size trials, however, the cultivar treatment significantly affected the foliar AUDPC response $(P \leq 0.001$ in both trials), as Russet Burbank showed a reduced rate of disease progress compared with Shepody and Red LaSoda (Fig. 1D and E).

During the period of the foliar epidemic, maximum daily temperatures ranged from 12 to $27^{\circ} \mathrm{C}$ (1998) and 19 to $35^{\circ} \mathrm{C}$ (1999), while minimum daily temperatures ranged from 1 to $11^{\circ} \mathrm{C}(1998)$ and 2 to $16^{\circ} \mathrm{C}$

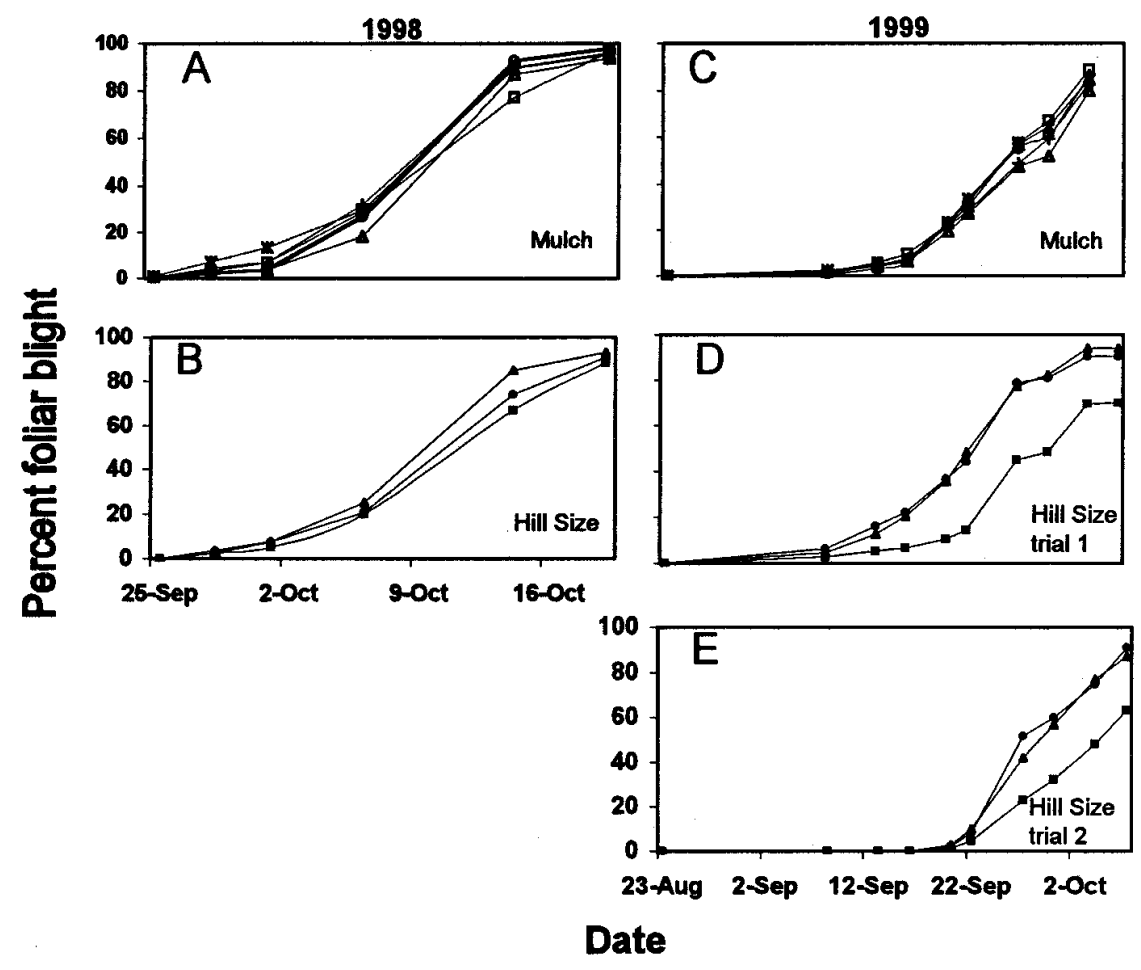

Fig. 1. Foliar disease progress curves for late blight epidemics in potato plots located near Corvallis, OR, during 1998 (A and B) and 1999 (C to E). A and B, disease progress curves for percent foliar late blight severity in plots of cv. Red LaSoda that received one of the following mulch treatments: no mulch $(+)$, polyurethane spray foam $(\square)$, black polyethylene film $(O)$, polyurethane spray foam and black polyethylene film $(\triangle)$, and copper hydroxide-treated textile $(*)$. Mulching treatments were not found to significantly affect foliar disease progress (AUDPC $1998 P=0.6910$; AUDPC $1999 P=0.7525)$. C to E, disease progress curves for whole plots of cvs. Red LaSoda (-), Shepody $(\boldsymbol{\Lambda})$, and Russet Burbank (ם), which were split to establish the hill size treatments. See text for analysis of effects of mulch or cultivar on areas under the disease progress curves. 
(1999). Soil temperatures measured in 1999 were intermediate to daily minimum and maximum air temperatures, with daily means in the range of 20 to $24^{\circ} \mathrm{C}$ during August then declining to 13 to $16^{\circ} \mathrm{C}$ in September (Fig. 2). Compared with the nomulch control, mulch treatments had a significant effect (paired $t$ test $P \leq 0.001$ with $35 \mathrm{df}$ ) on measured soil temperatures, although the differences were not large. Relative to no-mulch treatments, black polyethylene film raised the temperature of the soil in the hill by $0.5^{\circ} \mathrm{C}$, and black film combined with polyurethane spray foam raised the soil temperature by $1^{\circ} \mathrm{C}$; the copper hydroxide-treated textile lowered the soil temperature by $0.4^{\circ} \mathrm{C}$. Measurements of soil moisture, recorded in 1999 , also revealed differences among the five mulching treatments. Soils under the black polyethylene film and the polyethylene film plus spray foam were drier (average tensiometer readings of -1.0 and -1.2 $\mathrm{MPa}$, respectively) than soils in the nomulch treatment $(-0.9 \mathrm{MPa})$. Conversely, soils in the polyurethane spray foam and the copper hydroxide-treated textile treatments were moister (both averaged -0.5 $\mathrm{MPa}$ ) than the no-mulch control.

Mulching experiment. Tuber number and hill yield. Number of tubers per hill of cv. Red LaSoda was not affected in either year by any of the mulching treatments $(P$ $>0.1)$. The majority of the tubers were found in the intermediate depth in the hill (1998: $4.7 \pm$ (s.e.) 0.5, 1999: $5.0 \pm 0.5$ ) with smaller numbers being located in the shallow (1998: $1.0 \pm 0.2$, 1999: $1.1 \pm 0.2$ ) and deep regions (1998: $2.6 \pm 0.4,1999$ : $0.2 \pm 0.1)$. Polyurethane spray foam and black polyethylene film treatments did not significantly $(P>0.1)$ affect tuber yield per hill in either year. Yield per hill averaged $2.7 \pm 0.1 \mathrm{~kg}$ in 1998 and $2.4 \pm 0.1 \mathrm{~kg}$ in 1999. The copper hydroxide-treated textile significantly $(P \leq 0.01)$ affected yield only in 1998 when the average yield per hill in this treatment was $3.4 \pm 0.2 \mathrm{~kg}$ compared with $2.6 \pm 0.2 \mathrm{~kg}$ for the nomulch and black polyethylene film treatments.

Incidence of tuber blight. Tuber blight developed in all treatments but was more severe in 1998, when overall tuber blight incidence averaged $45 \%$, than in 1999 , when overall blight averaged $14 \%$. In both trials, tubers at shallower depths $(<15 \mathrm{~cm})$ showed higher incidences of blight than did tubers buried deeper than $15 \mathrm{~cm}$ (Fig. $3 \mathrm{~A}$ and $\mathrm{B})$. Black polyethylene film was a significant $(P \leq 0.01)$ main effect in both years; no evidence $(P>0.1)$ was obtained for an interaction between polyurethane spray foam and black film, or that spray foam alone had an effect on the incidence of blighted tubers. In 1998, the incidence of tuber blight in plots mulched with black polyethylene film averaged $32 \pm$ (s.e.) $4 \%$ compared with $56 \pm 4 \%$ in plots without this mulch; in 1999, incidence of tuber blight in plots mulched with polyethylene film averaged $9 \pm 3 \%$ compared with $20 \pm$ $3 \%$ in plots without this mulch. When tubers from different depths were analyzed separately, the black polyethylene film had stronger effects on tubers exposed to the hill surface $(1998, P \leq 0.001 ; 1999, P \leq$ 0.1 ) and on those covered with less than 15 cm of soil $(1998, P \leq 0.001 ; 1999, P \leq 0.1)$ than on tubers at depths $>15 \mathrm{~cm}$ below the

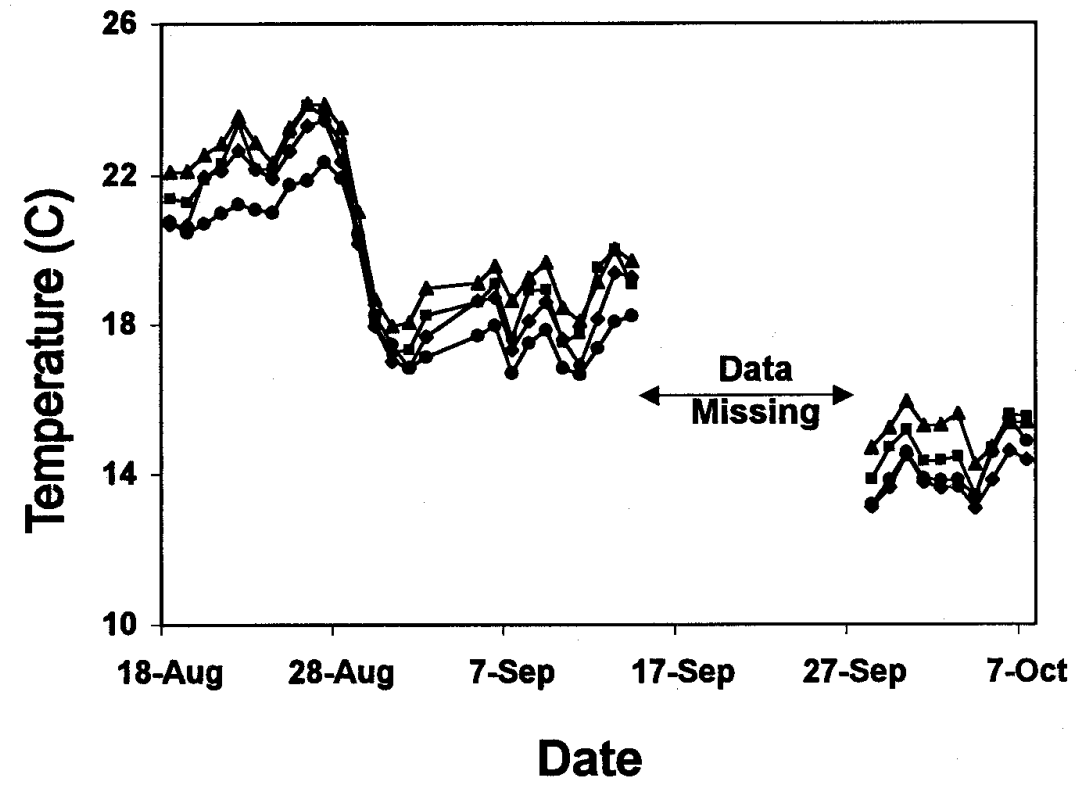

Fig. 2. Daily mean soil temperatures at $10 \mathrm{~cm}$ below the crest of the hill in the 1999 mulching trial. Soil temperatures graphed are the average of measurements made for potato hills that received the following mulching treatments: no mulch $(\bullet)$, black polyethylene film (অ), polyurethane spray foam and black polyethylene film $(\boldsymbol{\Lambda})$, and copper hydroxide-treated textile $(\mathbf{\bullet})$. Missing values in September resulted from a data transfer error. crest of the hill ( $P>0.1$ both years). For example, for tubers exposed at the hill surface in 1998 (Fig. 3A), black polyethylene film reduced the incidence of tuber blight relative to treatments without this mulch by $48 \%$, whereas the reduction for tubers covered with more than $15 \mathrm{~cm}$ of soil averaged only $3 \%$.

ANOVA comparison of the copper hydroxide-treated textile, black polyethylene film, and the no-mulch treatments revealed a significant treatment effect $(P \leq 0.01)$ on the incidence of blighted tubers that was consistent over both years (Fig. 4A and B). Blockage of water penetration into the hill by black polyethylene film reduced tuber blight incidence relative to the no-mulch treatment by $47 \pm 4 \%$ in 1998 and by $65 \pm$ $3 \%$ in 1999 . Mulching the potato hill with the water-permeable, copper hydroxidetreated textile led to tuber blight reductions of $61 \pm 4 \%$ in 1998 and $65 \pm 3 \%$ in 1999 .

Lesion confirmation and location on tubers. Ninety-seven percent of tubers incubated in 1999 to confirm diagnosis of late blight symptoms produced sporangia within 5 to 7 days after being placed into a moist chamber. In addition to late blight,

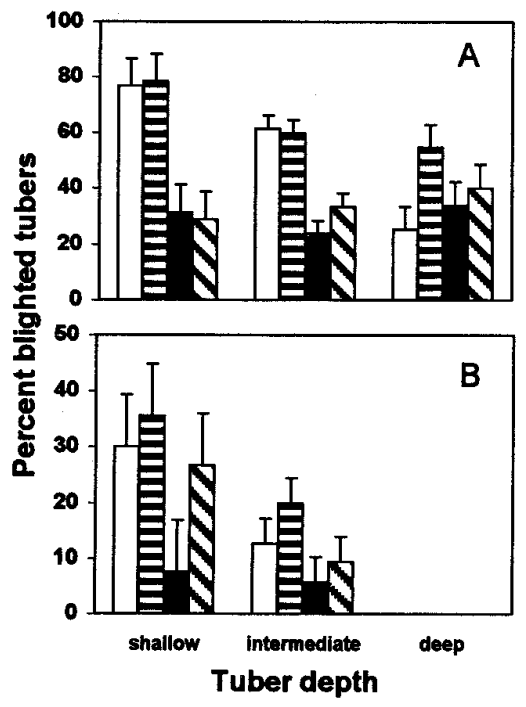

Fig. 3. Incidence of late blight caused by Phytophthora infestans on potato tubers at three depths in the potato hill for the four mulch treatments: no mulch (open bar), polyurethane spray foam (horizontally hatched bar), black polyethylene film (solid bar), and spray foam and black polyethylene film (diagonally hatched bar), A, during 1998 and B, during 1999. Shallow tubers were defined as partially exposed near the crest of the potato hill, intermediate tubers as completely covered with soil but less than $15 \mathrm{~cm}$ deep, and deep tubers as more than $15 \mathrm{~cm}$ below crest of hill. Bars represent the average of six potato hills harvested for each of seven (1998) or eight (1999) treatment replicates. Lines positioned on top of bars represent one standard error of the mean. In both seasons, the main effect of black polyethylene film significantly $(P \leq 0.01)$ reduced the incidence of tuber blight relative to the nomulch control. 
many tuber samples showed signs of additional rots including bacterial soft rots and rots caused by Fusarium species. When the morphological feature of the tuber at the center of the lesion could be identified, the majority of lesions were associated with eyes on the tuber or with the point of stolon attachment. In both years, the frequency distributions for lesion location on tubers grown under the black polyethylene film differed significantly $\left(\chi^{2}\right.$ test with 1 df, $P<0.001)$ from the distribution on tubers in the no-mulch treatment. The frequency of lesions on tubers in the nomulch control was $72 \%$ at eyes and $28 \%$ at the stolon end of the tuber in 1998, and $77 \%$ at eyes and $23 \%$ at the stolon end in 1999. Relative to this control treatment, black polyethylene film shifted 11 and $29 \%$ of the lesion distribution, in 1998 and 1999, respectively, from an eye on the tuber to the point of stolon attachment. No clear pattern emerged for lesion distribution on tubers in the copper hydroxidetreated textile treatment. In 1998, the proportion of lesions associated with eyes under the copper hydroxide-treated textile was $7 \%$ greater but not significantly different $(P>0.1)$ from the no-mulch control. This comparison differed significantly $(P \leq$ 0.001 ) in 1999 , however, as $49 \%$ of the lesion distribution relative to the no-mulch control was shifted from the eye to the point of stolon attachment.

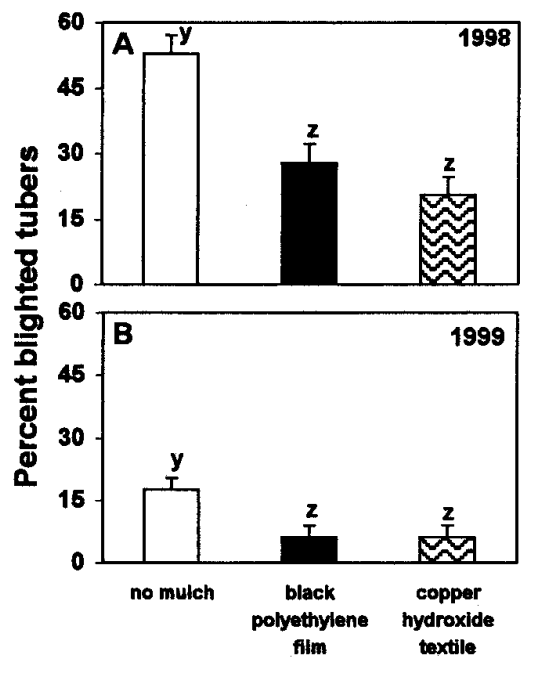

Treatment

Fig. 4. Incidence of tuber blight caused by Phytophthora infestans in potato cv. Red LaSoda treated with no mulch (open bar), a black polyethylene film (solid bar), or a copper hydroxidetreated agricultural textile (hatched bar). Experiments were conducted near Corvallis, OR, A, in 1998 and B, in 1999. Bars represent the average of six potato hills harvested for each of seven (1998) or eight (1999) treatment replicates. Lines positioned on top of bars represent one standard error of the mean. Within each panel, lowercase letters indicate significant differences $(P \leq 0.05)$ based on Fisher's protected least significant difference test.
Nonsymptomatic lesions at harvest. Nonsymptomatic tuber infection was present in both years; 16\% (1998) and 7\% (1999) of the tubers sampled from the mulching experiment developed symptoms of late blight after a month of cold storage. In $1998,16 \%$ of the no-mulch, $14 \%$ of the spray foam, $23 \%$ of the polyethylene film, $13 \%$ of the combined spray foam and polyethylene film, and $15 \%$ of the copper hydroxide-treated textile treatments were blighted. In 1999, blighted tubers averaged $17 \%$ of the no-mulch, $10 \%$ of the spray foam, $1 \%$ of the polyethylene film, $6 \%$ of the combined spray foam and film, and $2 \%$ of the copper hydroxide-treated textile samples.

Hill size experiment. Tuber number and hill yield. Over the three trials, neither treatment, i.e., potato cultivar or hill size, or their interaction showed a consistent effect on tuber number or yield per hill. In both years, however, the hill treatment significantly altered $(P \leq 0.001)$ the relative distribution of tubers found within each hill-depth classification (Fig. 5A, C, and $\mathrm{E}$ ). The number of tubers per hill in 1998, and the first and second trials of 1999, averaged $10.2 \pm$ (s.e.) $0.1,8.0 \pm 0.1$, and $8.3 \pm 0.2$ tubers, respectively. Yield per hill averaged $2.9 \pm 0.2,2.3 \pm 0.3$, and $2.4 \pm$ $0.2 \mathrm{~kg}$ in 1998 and the first and second 1999 trials, respectively.

Incidence of tuber blight. As in the mulching experiment, tuber blight developed in all plots in both years, and tubers exposed to the hill surface or covered by less than $15 \mathrm{~cm}$ of soil showed higher incidences of blight (34 \pm (s.e.) $7 \%$ and $20 \pm$ $4 \%$, respectively) than did the tubers covered with more than $15 \mathrm{~cm}$ of soil $(6 \pm$ $2 \%)$. The main effect of cultivar on the incidence of tuber blight was significant $(P$ $\leq 0.05)$ in all three trials, whereas hill size was significant $(P \leq 0.001)$ only in the 1998 experiment. No evidence $(P \geq 0.1)$ was obtained to indicate that an interaction between cultivar and size of the hill affected the incidence of blighted tubers. In each trial, tubers of Red LaSoda were the most diseased, followed by Shepody and then Russet Burbank (Fig. 6A to C), although in the second trial of 1999, the responses of Red LaSoda and Shepody were statistically similar. In the 1998 trial, tuber blight averaged $40 \pm 3 \%$ in the small hills, $30 \pm 3 \%$ in the medium hills, and 31 $\pm 3 \%$ in the large hills. Analysis of tuber blight incidence examined as a function of tuber depth, however, showed that size of the hill had very little effect on the incidence of blighted tubers, particularly those at intermediate depth classification, where the majority of tubers occurred (Fig. 5 B, $\mathrm{D}$, and $\mathrm{F}$ ).

Lesion location on tubers. When the morphological feature of the tuber at the center of the lesion could be identified, the majority of lesions were associated with eyes on the tuber and with the point of stolon attachment. Averaged over the three trials, for lesions on Russet Burbank tubers, $63 \%$ were associated with eyes and $19 \%$ with the stolon, for lesions on Shepody tubers, $61 \%$ were at eyes and $24 \%$ at the stolon, and for lesions on Red LaSoda tubers, $66 \%$ were located at eyes and $12 \%$ at the stolon. Nonsymptomatic tuber infection occurred in $7 \%$ of apparently healthy tubers sampled from the 1998 hill size trial and in 5 and $12 \%$ of tubers sampled from the first and second 1999 trials, respectively.

\section{DISCUSSION}

Experimental conditions in these experiments were highly conducive to the development of tuber blight by $P$. infestans, which allowed us to make relative comparisons of various barriers to movement of inoculum of $P$. infestans from potato foliage to developing tubers. Two barriers that covered the potato hills, black polyethylene film and copper hydroxidetreated agricultural textile, reduced the incidence of tuber blight relative to appropriate controls, whereas the other barriers investigated, polyurethane spray foam applied in the area of the hill immediate to the potato stem and additional soil in the hill profile, had little effect on tuber blight incidence. In spite of some success in preventing infection with the two hill coverings, however, tuber blight was never reduced to a level that would meet industrial standards. Consequently, in addition to providing insight on how inoculum of $P$. infestans moves from foliage to tubers, we believe the data also highlight the difficulty of direct suppression of tuber blight in a field with barriers once the foliar stage of the disease has been allowed to develop.

Black polyethylene film was one of the two partially effective barriers for the suppression of tuber blight. The effectiveness of this barrier as a deterrent to tuber blight may be attributable to two reasons: the blocking of water, and thus inoculum, from infiltrating the potato hill, and alteration of the soil environment within the hill. Hills covered with black plastic were drier and slightly warmer than uncovered hills, thus potentially affecting inoculum movement and infection capacity. The copper hydroxide-treated textile, unlike the polyethylene film, allowed water to penetrate the potato hill, resulting in a soil water content that was similar to the no-mulch control. In addition, the textile covering the hill slightly lowered soil temperatures relative to the no mulch control. Therefore, given little effect of the textile on soil moisture and temperature within the hill, we attribute the effectiveness of this mulch to the coating of copper hydroxide $\left(6 \mathrm{~g} / \mathrm{m}^{2}\right)$ applied to the textile. Copper hydroxide has long been known to be an effective fungicide for late blight control and has been shown to kill both sporangia and zoospores in soil (5-7). 
With regard to mechanism or paths of inoculum movement into the hill, the success of the black polyethylene film and the copper hydroxide-treated textile for reduction of tuber blight suggests that movement of pathogen propagules is not restricted solely to large openings in the soil such as the potato stem channels Lacey $(13,14)$ described. Thus, while channels in the soil undoubtedly allow inoculum to penetrate into the soil $(13,23)$, they do not appear to be an essential factor leading to tuber blight infection. In fact, our attempt to alter the channeling of water down plant stems through blockage of the potato stem area with polyurethane spray foam had no effect on reducing tuber blight incidence. For several reasons, however, the spray foam mulch applied in the stem area was not an ideal treatment in this study. First, the polyurethane spray foam treatments were not completely successful at sealing the stem channel as an avenue to inoculum travel. To examine how tightly the spray foam sealed the area, during harvest we examined the moisture patterns under the combined treatment of black polyethylene film and polyurethane spray foam and noted that the soil near the potato stem was typically damper than soil further from the stem. Thus, the spray foam plug was only partially effective in preventing the infiltration of inoculum-laden water from the area immediate to the potato stem. Second, the PVC pipe, which we used to separate the stem area from the rest of the hill, may have created artificial, albeit shallow, channels in which the water and inoculum could travel to infect tubers. Third, Red LaSoda, the potato cultivar grown in the mulching experiment, grew top-heavy with sprawling vines during the period of the epidemic. Lacey (15), when investigating water deposition on the hill and how it related to inoculum reaching tubers, often associated water channeling down stems with potato cultivars that had upright growth. Perhaps our conclusions, which contrast those of Lacey $(13,14)$, are dependent partially on the growth habit of Red LaSoda.

Interestingly, the frequency distributions of likely sites of infection on tubers suggest that both avenues, soil penetration of inoculum from anywhere on the hill surface and movement of inoculum down the stem channels, may be involved. For example, when black polyethylene film was used alone, the number of lesions located at eyes decreased while the number associated with the stolon end increased relative to the no-mulch distribution, suggesting that this treatment shifted the relative inoculum concentrations to higher proportions in the region immediate to the potato stem. This finding agrees with Lacey (14), who noted in a severe late blight infection in 1960 that lesions on tubers close to the surface of the potato hill were most often associated with eyes, whereas many of the lesions on deeper blighted tubers appeared to be initiated near the stolon.

The higher incidence of blight in tubers close to the surface of the potato hill than in deeply buried tubers has been noted in other studies $(8,13,16)$ and was usually attributed to ability of inoculum to reach the tubers. Perhaps most surprising in this experiment, however, were the relatively high incidences of blight on tubers that were deep in the hill profile during 1998, and the fact that none of the barriers affected the incidence of blight in these tubers. These findings suggest that the inoculum is capable of penetrating some distance in the soil, although the source and pathway of this inoculum movement is unclear. Other possible explanations for the high incidence of blight in the deep tubers are secondary tuber-to-tuber infections initiated either in the field (15) or during the storage period before assessment (4), or tuber blight infection initiated during the
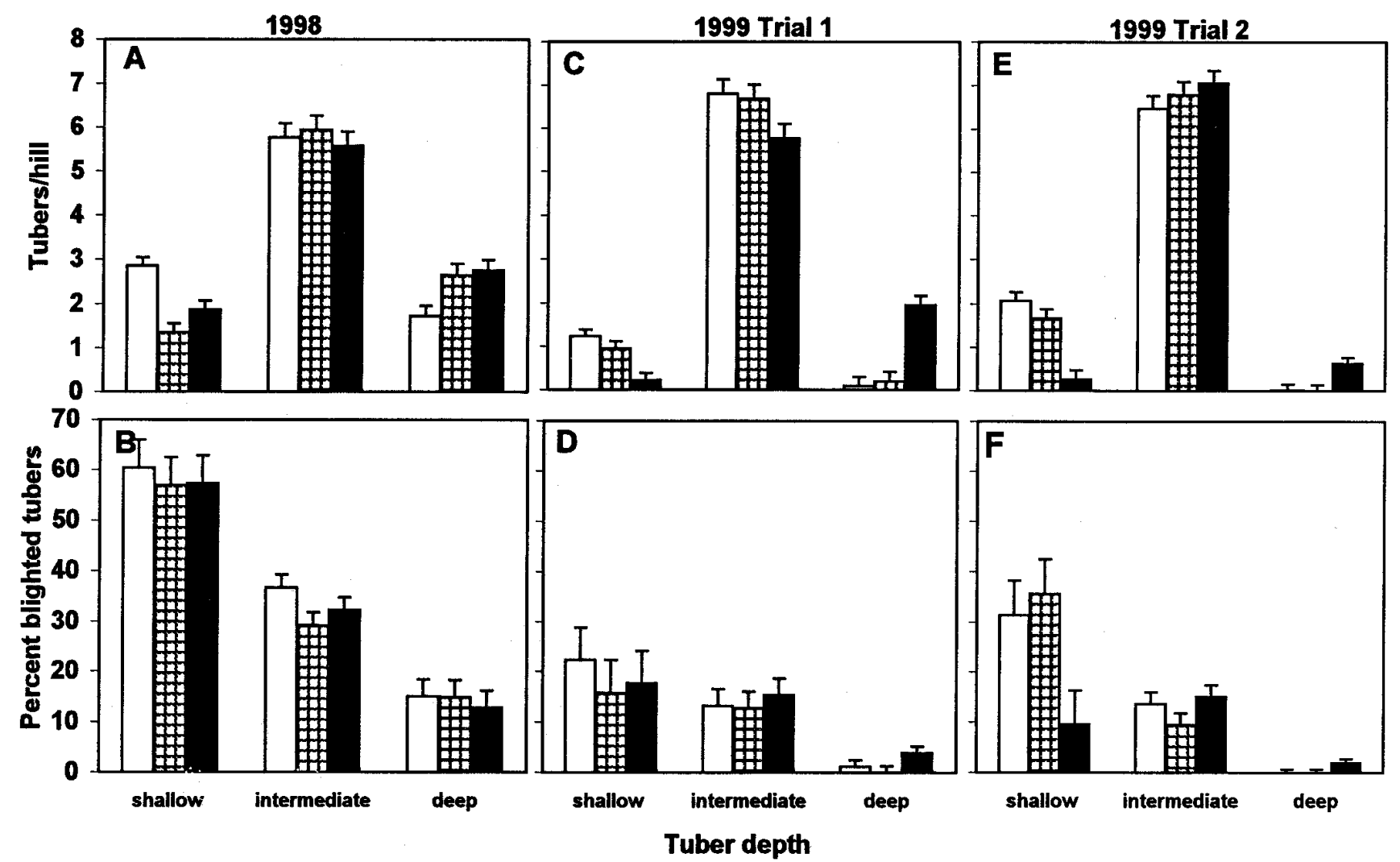

Fig. 5. Average number of potato tubers per hill $(\mathbf{A}, \mathbf{C}$, and $\mathbf{E})$ and the incidence of tuber blight caused by Phytophthora infestans $(\mathbf{B}, \mathbf{D}$, and $\mathbf{F})$ at three tuber depths in the hill in small, medium, and large hill sizes in an experiment conducted near Corvallis, OR, A and B, in 1998 and $\mathbf{C}$ to F, in 1999. Tuber number and blight incidence are averaged over the three potato cultivars, Red LaSoda, Russet Burbank, and Shepody, for tubers grown in small hills (open bar), medium hills (checked bar), and large hills (solid bar). Shallow tubers were defined as partially exposed near the crest of the potato hill, intermediate tubers as covered with soil but less than $15 \mathrm{~cm}$ deep, and deep tubers as more than $15 \mathrm{~cm}$ below crest of hill. The bars represent means of six treatment replicates. Lines positioned on top of bars represent one standard error of the mean. 
harvest procedure. We discount both these mechanisms, however, because at the time of harvest, most lesions on deep tubers were of a similar size and severity to lesions on shallower tubers.

From a practical perspective, hilling is the most common recommendation given for direct suppression of tuber infection by $P$. infestans. While we did find that deeper tubers were less likely to become infected than shallow to intermediate tubers, it was somewhat unexpected that the practice of hilling had almost no value in terms of tuber blight suppression, at least for the hill sizes and the soils used in this study. This result was consistent over the three cultivars studied: Red LaSoda, Shepody, and Russet Burbank. For the majority of the tubers, i.e., those growing in intermediate regions of the hill, no difference in the incidence of tuber blight could be attributed to the amount of soil covering the tubers. This result is in direct contrast to Lacey's (14) conclusions from a distribution study of blighted and healthy tubers within potato hills, where he found more

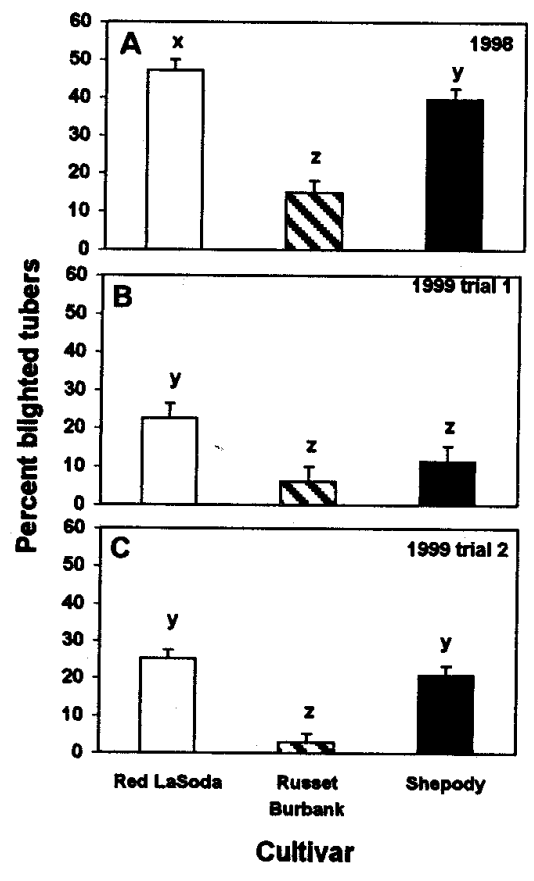

Fig. 6. Incidence of tuber blight caused by Phytophthora infestans for potato cultivars Red LaSoda (diagonally hatched bar), Russet Burbank (solid bar), and Shepody (open bar), grown in three hill sizes (small, medium, and large) in an experiment conducted near Corvallis, OR, A, in 1998 and $\mathbf{B}$ and C, in 1999. The hill size treatments were established by hilling with the planter only (small hill) and by supplementary hilling once or twice with tractormounted disks after potato emergence (medium and large hills, respectively). Bars represent means of six treatment replicates. Lines positioned on top of bars represent one standard error of the mean. Within each panel, different lowercase letters indicate significant differences $(P \leq 0.05)$ based on Fisher's protected least significant difference test. infections on shallow tubers and stressed the importance of "good ridging" to reduce the potential for blighted tubers. In the hill size experiment, the intermediate and large hill sizes were typical of hill sizes used in many irrigated commercial fields in the United States. Unfortunately, hills of this size, while useful in terms of prevention of tuber sunscald and weed suppression, are apparently not large enough to prevent $P$. infestans inoculum from reaching tubers and initiating blight.

From a more positive perspective, the hill size experiment did demonstrate the value of host resistance. The three cultivars chosen are susceptible to $P$. infestans, but Russet Burbank is ranked only moderately susceptible, as shown in this experiment by a delayed foliar epidemic and a lower incidence of tuber blight. The relative frequencies of tuber blight we observed for Shepody and Russet Burbank agree with a previous field ranking of several potato cultivars inoculated with US-11 genotype of the pathogen (12). While Red LaSoda had a low incidence of tuber blight in the one year it was included in that cultivar trial (12), the high tuber blight incidence in Red LaSoda observed in our study may better reflect its susceptibility.

The soil temperatures measured during 1999 suggest that soil conditions were conducive for the indirect germination of sporangia to zoospores $(13,20,23)$. Consequently, zoospores may have been the principal type of inoculum initiating tuber blight in these experiments, although we never directly identified the form of inoculum. On a relative scale, tuber blight initiated by zoospores is thought to be more important than tuber blight initiated by sporangia, since zoospores are motile and are also able to follow chemical gradients of potato root exudates, which increases their likelihood of contacting tubers $(13,20,23)$.

When assessing resistance to tuber blight in potato cultivars, Dorrance and Inglis (3) noted that pre- and post-storage evaluations of tuber blight were necessary to achieve reliable results. In the mulching and hill size experiments, after a month of cold storage, tuber blight was present in tubers that were nonsymptomatic at harvest. Incidence of tuber blight after storage was quite variable, however, and did not provide any additional information on the effects of the barrier treatments on tuber infection.

Clearly, tuber blight is difficult to control in an environment conducive to disease. These experiments demonstrate that inoculum of $P$. infestans can effectively move from foliage to tuber, and also highlight the difficulty of achieving direct tuber blight control through the use of cultural barriers. Our inability to reduce tuber blight to a suitable level of control by any of the cultural manipulations suggests that suppression of tuber infection may be bet- ter achieved by prevention of foliar epidemics or through the use of host resistance.

\section{ACKNOWLEDGMENTS}

Research was supported in part by the USDACSREES Western Region Integrated Pest Management Special Grants Program. We thank Teresa Sawyer, Robin Ludy, Aaron Henderson, and Jim Fell for their technical assistance, and Joy Jaegner for providing $P$. infestans isolates. We are grateful to the Texel company (Saint-Elzéar-de-Beauce, Quebec, Canada) for donating the copper hydroxide-treated agricultural textile, Tex-R-Pro, used in this study.

\section{LITERATURE CITED}

1. Adams, M. J. 1975. Potato tuber lenticels: Susceptibility to infection by Erwinia carotovora var. atroseptica and Phytophthora infestans. Ann. Appl. Biol. 79:275-282.

2. Bashan, B., Kadish, D., Levy, Y., and Cohen, Y. 1989. Infectivity to potato, sporangial germination, and respiration of isolates of Phytophthora infestans from metalaxyl-sensitive and metalaxyl-resistant populations. Phytopathology 79:832-836.

3. Dorrance, A. E., and Inglis, D. A. 1998. Assessment of laboratory methods for evaluating potato tubers for resistance to late blight. Plant Dis. 82:442-446.

4. Dowley, L. J., and O'Sullivan, E. 1991. Sporulation of Phytophthora infestans (Mont.) de Bary on the surface of diseased tubers and tuber to tuber spread during handling. Potato Res. 34:295-296.

5. Dubey, T., James, R. V., and Stevenson, W. R. 1997. Effect of fungicide on viability of Phytophthora infestans sporangia in soil. (Abstr.) Phytopathology 87:S26.

6. Dubey, T., James, R. V., and Stevenson, W. R. 1998. The effect of 15 fungicides on viability of Phytophthora infestans sporangia in soil. (Abstr.) Phytopathology 88:S23.

7. Dubey, T., James, R. V., and Stevenson, W. R. 1999. The effect of fungicides on germination of Phytophthora infestans zoospores in soil. (Abstr.) Phytopathology 89:S21.

8. Dubey, T., and Stevenson, W. R. 1996. Factors affecting the movement and viability of sporangia of Phytophthora infestans in soil. (Abstr.) Phytopathology 86:S61-62.

9. Fry, W. E., and Goodwin, S. B. 1997. Reemergence of potato and tomato late blight in the United States. Plant Dis. 81:1349-1357.

10. Fry, W. E., and Goodwin, S. B. 1997. Resurgence of the Irish potato famine fungus. Bioscience 47:363-371.

11. Hirst, J. M., Stedman, O. J., Lacey, J., and Hide, G. A. 1965. The epidemiology of Phytophthora infestans. IV. Spraying trials, 1959 to 1963, and the infection of tubers. Ann. Appl. Biol. 55:373-395.

12. Inglis, D. A., Johnson, D. A., Legard, D. E., Fry, W. E., and Hamm, P. B. 1996. Relative resistances of potato clones in response to new and old populations of Phytophthora infestans. Plant Dis. 80:575-578.

13. Lacey, J. 1965. The infectivity of soils containing Phytophthora infestans. Ann. Appl. Biol. 56:363-380.

14. Lacey, J. 1966. The distribution of healthy and blighted tubers in potato ridges. Eur. Potato J. 9:86-96.

15. Lacey, J. 1967. The role of water in the spread of Phytophthora infestans in the potato crop. Ann. Appl. Biol. 59:245-255.

16. Lacey, J. 1967. Susceptibility of potato tubers to infection by Phytophthora infestans. Ann. Appl. Biol. 59:257-264.

17. Lambert, D. H., and Currier, A. I. 1997. Differences in tuber rot development for North American clones of Phytophthora infestans. 
Am. Potato J. 74:39-41.

18. Large, E. C. 1953. The interpretation of progress curves for potato blight and other plant diseases. Plant Pathol. 1:109-117.

19. Rowe, R. C., and Secor, G. A. 1993 . Managing potato health from emergence to harvest. Pages 35-57 in: Potato Health Management. R. C. Rowe, ed. American Phytopathological
Society, St. Paul, MN.

20. Sato, N. 1979. Effect of soil temperature on the field infection of potato tubers by Phytophthora infestans. Phytopathology 69:989993.

21. Tooley, P. W., Swiegard, J. A., and Fry, W. E. 1986. Fitness and virulence of Phytophthora infestans isolates from sexual and asexual populations. Phytopathology 76:1209-1212

22. Walmsley-Woodward, D. J., and Lewis, B. G. 1977. Laboratory studies of potato tuber resistance to infection by Phytophthora infestans. Ann. Appl. Biol. 85:43-49.

23. Zan, K. 1962. Activity of Phytophthora infestans in soil in relation to tuber infection. Trans. Br. Mycol. Soc. 45:205-221. 